
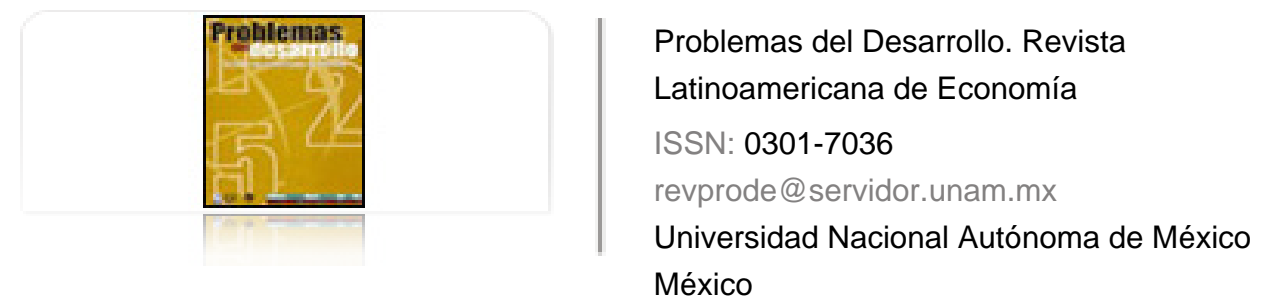

Paz Antolín, María José

Ajuste estructural e informalidad en Guatemala

Problemas del Desarrollo. Revista Latinoamericana de Economía, vol. 39, núm. 155, octubre-

diciembre, 2008, pp. 153-179

Universidad Nacional Autónoma de México

Distrito Federal, México

Disponible en: http://www.redalyc.org/articulo.oa?id=11820123008

Cómo citar el artículo

Número completo

- Más información del artículo

Página de la revista en redalyc.org

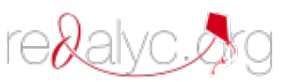

Sistema de Información Científica

Red de Revistas Científicas de América Latina, el Caribe, España y Portugal Proyecto académico sin fines de lucro, desarrollado bajo la iniciativa de acceso abierto 


\title{
AJUSTE ESTRUCTURAL E INFORMALIDAD EN GUATEMALA
}

\author{
María José Paz, Antolín* \\ Fecha de recepción: 21 de abril de 2008. Fecha de aceptación: 8 de agosto de 2008.
}

\section{Resumen}

Debido a la relevancia de las reformas económicas aplicadas para el desempeño económico de las últimas dos décadas son necesarios estudios que analicen estos vínculos. Éste es el objetivo del presente trabajo que se centra en la economía guatemalteca y en la evolución de sus condiciones laborales. El análisis tiene presente los rasgos comunes de las políticas de reforma llevadas a cabo pero se centra en lo distintivo del caso guatemalteco. En este sentido, destacan el contexto político y social y la particular forma de inserción en la economía mundial. Los distintos indicadores estudiados muestran cómo se ha producido un deterioro de las condiciones laborales, sobre todo por el crecimiento de la informalidad. Aunque éste ha sido un fenómeno típico en Guatemala su evolución presenta elementos novedosos vinculados precisamente con las políticas de ajuste.

Palabras clave: Guatemala, políticas económicas, ajuste estructural, condiciones laborales e informalidad.

\section{Summary}

Given the relevance of the economic reforms applied to economic performance in the last twenty years, studies are needed to analyze these links. This is the aim of the present work which focuses on the Guatemalan economy and on the evolution of its labor conditions. The analysis presents the common features of the reform policies carried out, but focuses on the what is distinctive in the Guatemalan case. In this sense, the politico-social context stands out, as does its particular form of insertion into the world economy. The different indicators studied show how the deterioration in labor conditions has been produced, above all by the growth of informality. Although this has been a typical phenomenon in Guatemala its evolution presents new elements linked precisely to the adjustment policies.

Key words: Guatemala, economic policies, structural adjustment, labor conditions and informality.

* Catedrática interina del Departamento de Economía Aplicada I, Facultad de Ciencias Económicas y Empresariales, Universidad Complutense de Madrid. Correo electrónico: mjpazant@ccee.ucm.es. 
Résumé

En raison de l'importance des réformes économiques des dernières décennies appliquées en vue d'une plus grande efficience économique, des études qui analysent leurs conséquences sont nécessaires. C'est l'objectif de ce travail qui est centré sur l'économie guatémaltèque et l'évolution des conditions de travail dans ce pays. Cette analyse prend en compte les points communs des politiques de réforme menées mais se centre sur les traits distinctifs du cas guatémaltèque. Dans ce sens, le contexte politique et social et la forme particulière d'insertion de ce pays dans l'économie mondiale ressortent notablement. Les divers indicateurs étudiés montrent comment une détérioration des conditions de travail s'est produite, surtout au travers $d u$ développement de l'économie informelle. Bien que celle-ci ait toujours été un phénomène typique au Guatemala, son évolution présente des éléments nouveaux liés précisément aux politiques d'ajustement.

Mots clés: Guatemala, politiques économiques, ajustement structurel, conditions de travail et économie informelle.

\section{Resumo}

Por causa da relevância das reformas econômicas aplicadas para o desempenho econômico das últimas duas décadas são necessários estudos que analisem esses vínculos. Esse é o objetivo do presente trabalho que se centra na economia da Guatemala e na evolução das condições laborais dessa nação. A análise considera os rasgos comuns das políticas de reforma realizadas, mas se concentra no particular do caso da Guatemala. Neste sentido se destacam tanto o contexto político quanto social e a particular forma de inserção na economia mundial. Os diferentes indicadores que se estudaram mostram como se deterioraram as condições laborais, sobre tudo pelo incremento da informalidade. Ainda que este é um fenômeno típico na Guatemala, sua evolução apresenta novos elementos justamente vinculados com as políticas de ajuste. Palavras chave: Guatemala, políticas econômicas, ajuste estrutural, condições laborais e informalidade. 


\section{Introducción}

$\varepsilon$

n el ámbito mundial, los últimos 25 años se han caracterizando por la aplicación

de las llamadas "políticas de ajuste". La región latinoamericana no ha sido una

excepción, sino todo lo contrario: ha sido pionera en la puesta en marcha de dichas políticas y una de las regiones donde éstas han adquirido mayor radicalidad y donde, a su vez, los resultados han sido más insatisfactorios (Ffrench-Davis, 2005).

La forma adoptada ha variado de unos países a otros, en donde los factores políticos, económicos o culturales han condicionado su distinta materialización. Sin embargo, para entender sus determinantes es importante no olvidar el carácter prácticamente universal con el que se han venido aplicando, pues permite entender la génesis de dichas políticas en la necesidad del sistema capitalista de dar una respuesta a la crisis de los años setenta. Si las medidas han tenido éxito o fracaso, depende de la perspectiva adoptada y de las variables que son prioritarias en el análisis. Lo que no cabe duda es que ya ha transcurrido tiempo suficiente para someterlas a estudio y, de hecho, es abundante la bibliografía en el tema. El objetivo de este trabajo es el mismo, aunque con algunos rasgos distintivos.

a) El primero de ellos resulta de considerar la necesidad de profundizar en las características particulares de este proceso en los distintos países. Aunque es cierta su aplicación más o menos generalizada a un grupo amplio de economías - y también la de muchos de sus resultados- no lo es menos la especificidad que ha adoptado en cada caso. Así, frente a los estudios que analizan el impacto en la región latinoamericana (lo que permite destacar los rasgos y tendencias comunes, tarea indudablemente necesaria), en este caso nosotros hemos preferido incidir en las particularidades concretas de una economía. El objetivo es tratar de identificar no sólo los efectos finales sino también los mecanismos concretos que llevan a ellos.

Para cumplir con este propósito nos parece necesario atender las especificidades de cada economía. Metodológicamente, ello nos lleva a incidir más en la descripción e interpretación de los mecanismos y en la valoración cuantitativa y cualitativa de los efectos que en la comprobación matemática de una correlación significativa entre éstos y sus posibles causas.

En general, consideramos que hay dos aspectos particulares de cada país que han influido en la forma particular que ha adoptado el proceso: i) su estructura económica y, especialmente su inserción exterior; y ii) la coyuntura política nacional. Elegimos el caso guatemalteco para nuestro estudio porque - además de otras razones que se expondrán más adelante y porque no es el único- ilustra la 
importancia de estos dos aspectos para determinar los rasgos definitivos del ajuste y sus resultados: ${ }^{1}$

- El primer aspecto permite elevar el protagonismo de las medidas de ajuste orientadas a "mejorar" la inserción externa, aunque lo que hacen es perpetuar aún más el carácter dependiente y espurio de la misma. Ello marca una distancia con respecto a otros países, en los que los problemas de deuda externa o la abundancia de recursos naturales han dado lugar a "ajustes" diferentes.

- El segundo permite alterar algunos de los contenidos típicos de las reformas. El aumento del gasto público, sobre todo el social, en un contexto marcado a priori por políticas fiscales restrictivas es el ejemplo más evidente de ello.

b) Junto a lo mencionado en el apartado anterior, el segundo de los rasgos distintivos de este trabajo es el que hace referencia a las variables sobre las que se va a valorar el impacto y que son el ingreso y las condiciones laborales, con especial atención al fenómeno de la informalidad. Esta orientación refuerza también la elección del caso guatemalteco por ser uno de los países de la región con mayor protagonismo de este fenómeno, tanto en el ámbito histórico como en el actual.

La hipótesis es que en términos generales las políticas económicas aplicadas en Guatemala en las dos últimas décadas han tenido un impacto negativo en el ingreso y en las condiciones laborales, sobre todo en el auge de la informalidad.

A pesar de la aparente mejora de ciertos indicadores, mostraremos cómo la situación general de los trabajadores ha experimentado una regresión importante, fruto sobre todo de la creciente informalidad. Si en 1989 el porcentaje de los trabajadores guatemaltecos informales era de 67\%, en 2004 esta cifra aumentó a 69\% (según fuentes nacionales) y a 75\% (según estimaciones de la Organización de las Naciones Unidas, ONU). ${ }^{2}$ Nuestro propósito es establecer vínculos entre este aumento de la informalidad y las políticas económicas aplicadas.

1 En el marco de este trabajo por razones de tiempo y espacio no será posible atender a las particularidades de otras economías, aunque en ocasiones se sugieran algunas comparaciones que puedan ayudar a entender mejor lo distintivo del caso guatemalteco. A pesar de ello este trabajo pretende aportar desde una perspectiva metodológica al posible estudio de otras economías nacionales.

2 Somos conscientes de la debilidad de algunos de los indicadores que oficialmente se utilizan para medir el fenómeno de la informalidad, sobre todo a la hora de establecer comparaciones históricas y geográficas. Por ello siempre que ha sido posible hemos tratado de completar esta información con otros estudios realizados por fuentes no oficiales, tal vez más cercanas al fenómeno objeto de estudio. 
El periodo de análisis abarca desde finales de los ochenta de la década pasada, cuando comienzan a adoptarse de forma sistemática y generalizada las políticas típicas de estabilización y ajuste estructural, hasta la actualidad. De algunos indicadores será difícil mostrar información que cubra todo el periodo de estudio e incluso habrá otros de los que no se podrá mostrar ningún dato. A pesar de ello creemos que la información recogida es más que suficiente para conocer la evolución de las variables señaladas.

El trabajo se estructura en tres apartados: en el primero se abordan las particularidades del "modelo" de ajuste en Guatemala; en el segundo se expone una batería de indicadores que permiten contrastar las implicaciones que han tenido dichas políticas para las condiciones laborales; por último, se resumen las principales conclusiones.

\section{Los intentos por estabilizar la economía y mejorar la inserción externa: el ajuste estructural en Guatemala}

\section{Tendencias generales}

Cuando se habla de las reformas económicas aplicadas en las últimas décadas es frecuente la distinción entre políticas de estabilización y políticas de ajuste estructural. Las primeras, más orientadas a repercutir en el corto plazo, tendrían precisamente como objetivo el de estabilizar los principales indicadores macroeconómicos, sobre todo la inflación; las segundas, con un horizonte temporal más largo, pretendían una transformación de la estructura productiva y exportadora para mejorar la inserción en el mercado mundial, resolver los desequilibrios comerciales y potenciar el crecimiento, en especial por medio de las exportaciones. ${ }^{3}$ Denominadas también como políticas de oferta o neoliberales, han venido marcadas por una serie de ejes más o menos comunes entre los que destacan: la reforma fiscal (generalmente regresiva) y el equilibrio presupuestario, la liberalización, desregulación y apertura externa tanto en el terreno comercial como en el financiero y productivo, la desregulación del mercado laboral y la reforma del Estado mediante la reducción de la participación de éste en la economía (las privatizaciones han sido el ejemplo más visible de esta reforma pero no el único). ${ }^{4}$

3 Ello es lo que en ocasiones también se ha llamado la "estrategia de desarrollo hacia fuera" en sustitución de la "estrategia de desarrollo hacia dentro" que habría caracterizado los años de la industrialización por sustitución de importaciones (ISI).

4 Un análisis más amplio del contenido de estas políticas se puede obtener en el trabajo de Williamson (1989) o, desde una perspectiva crítica, el de Arrizabalo (1995) o Crotty (2000). 
A partir de estas tendencias generales, profundizamos ahora en el caso guatemalteco.

\section{El contexto político y económico en Guatemala}

A principios de los años ochenta Guatemala experimentó una crisis aguda que vino a interrumpir casi tres décadas de crecimiento continuo a un promedio de 5\% anual. Esta crisis hundía sus raíces en el agotamiento del propio modelo de crecimiento basado en la agricultura de exportación, al que se había unido desde los sesenta un particular modelo de industrialización por sustitución de importaciones. Pero, a diferencia de otros países de la región, en Guatemala la crisis de este modelo no dio lugar a un problema grave de sobreendeudamiento, aunque sí a la agudización de los desequilibrios comerciales.

Las manifestaciones de esta crisis fueron más allá de lo estrictamente económico. A finales de los sesenta y principios de los ochenta se produce un recrudecimiento del conflicto armado que alcanza las cotas más altas de violencia y represión desde que se originara en la década de los sesenta. Todo ello crea un contexto interno adecuado para la puesta en marcha de medidas que favorezcan la "salida" a la crisis económica y política. Este proceso político y los recursos internacionales que lo acompañaron contribuyeron a legitimar y a "suavizar" las políticas de ajuste económico. No en vano, los propios Acuerdos de Paz reconocen entre las causas del conflicto las enormes desigualdades de renta y plantearon la necesidad de políticas que las mitiguen. El aumento del gasto social o del salario mínimo serán algunas de ellas.

\section{El contenido de las reformas}

Desde una perspectiva temporal, la puesta en marcha del ajuste se caracteriza por el retraso en su inicio con respecto a otros países de la región, precisamente como resultado de ese contexto político. Además, la ausencia de un programa específico y la influencia de conflictos internos entre las cúpulas empresariales han contribuido al desorden y a la falta de coherencia en la secuencia del ajuste [Asociación para el Avance de las Ciencias Sociales (AVANCSO)1998:22].

Con la descripción del Programa de Naciones Unidas para el Desarrollo (PNUD) (2002:71 y ss) podemos identificar dos ejes mediante los cuales se aplican las reformas: los ajustes interno y el externo. Su contenido constituye el elemento crucial para determinar el modelo de crecimiento que se impone tras la crisis. Lo que pre- 
tendemos es valorar si ese modelo resulta positivo en términos de empleo, ingresos y, más concretamente, cómo ha influido en la creciente informalidad. ${ }^{5}$ Para ello es importante analizar algunos de sus elementos.

La política monetaria y fiscal. En este sentido, los cambios se inician en Guatemala a finales de los ochenta con el Programa de Reordenamiento Económico y Social de Corto Plazo (PRES) del presidente Vinicio Cerezo Arévalo. Nuestro caso de estudio presenta pocas novedades con respecto a lo acontecido en otras naciones. Se pone en marcha una política monetaria restrictiva ${ }^{6}$ (con un breve paréntesis entre 1996 y 1999) que trae como resultado un aumento sin precedentes de los tipos de interés, al mantenerse durante buena parte de la década de los noventa en niveles superiores a 20\%. Ello supone evidentes consecuencias en términos de estancamiento de la inversión productiva.

Lo más novedoso en los programas de estabilización vendrá representado por la política fiscal. Ésta constituye el segundo instrumento del ajuste interno y refleja las contradicciones y dificultades con las que se ha encontrado la política de estabilización en Guatemala. Además, para nuestro objeto de estudio el contenido y resultados de esta política resultan especialmente relevantes, pues la misma puede convertirse o no en uno de los principales mecanismos redistributivos que opere en favor de los estratos de menores ingresos de la población. Hasta principios de los noventa ésta no era la situación que había venido caracterizando la política fiscal en Guatemala. Las razones eran dos sobre todo: a finales de los años ochenta Guatemala era el país latinoamericano con una menor carga tributaria (ingresos fiscales/Producto Interno Bruto, PIB); por otra parte el gasto social también se encontraba entre los más bajos de la región (véase gráfica 1).

A pesar de ello y de las urgentes necesidades en materia de inversiones sociales, desde principios de los noventa la estabilización macroeconómica exigía un presupuesto fiscal equilibrado, lo que obligaba a una contención del gasto público. De hecho, éste pasó de representar 10.2 \% del PIB en 1990 a 9.2 en $1995 .^{7}$

5 Un planteamiento similar, aunque con metodología diferente, es el que desarrolla Hammill (2007) al intentar valorar si el modelo de crecimiento es favorable a los pobres.

6 Sobre todo mediante la venta de títulos de deuda por parte del Banco de Guatemala y el aumento de las reservas exigidas a los bancos (PNUD, 2002:79-80).

7 Cualquiera de estas cifras contrasta con la media de los países de la Organización para la Cooperación y el Desarrollo Económicos (OCDE), donde el gasto público representa más de $40 \%$ o con las de otros países latinoamericanos con niveles cercanos a $20 \%$.

Vol. 39, núm. 155, octubre-diciembre / 2008

$\underset{\text { DeSarrollo }}{\text { PRR }}$ 
Gráfica 1

Gasto público e ingresos fiscales como porcentaje del PIB

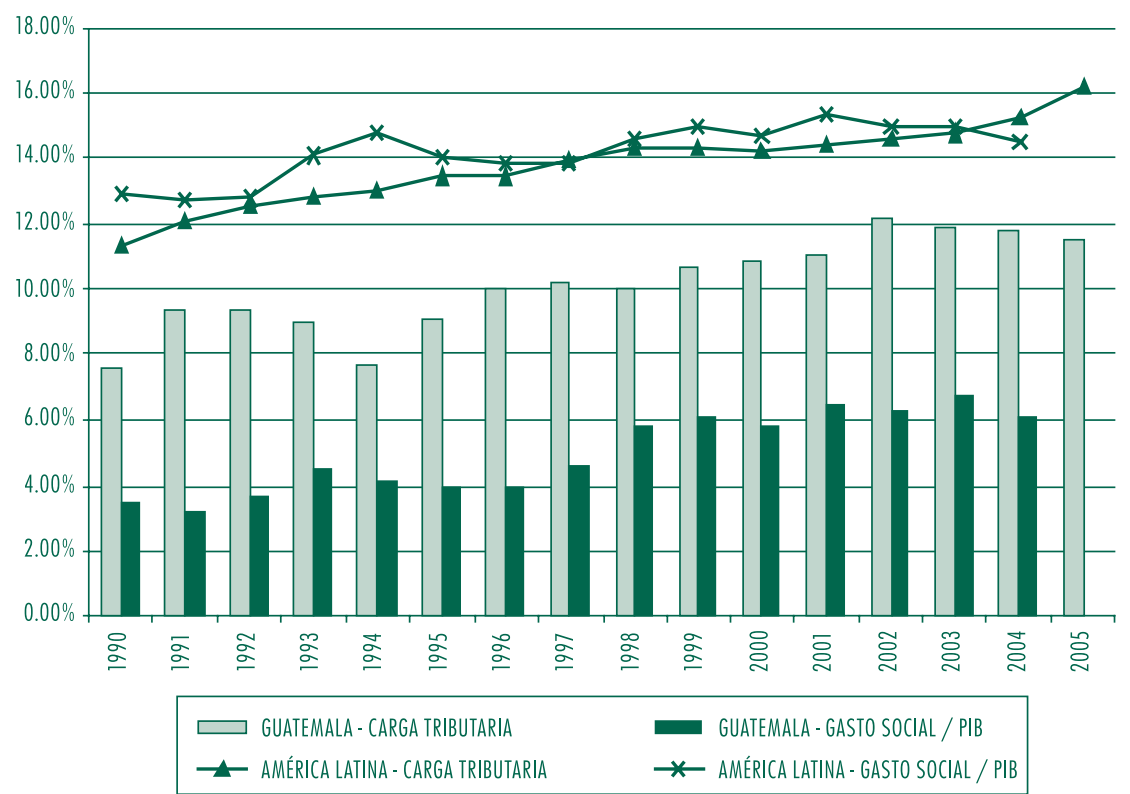

Fuente: Banco de Guatemala y CEPAL.

Pero los Acuerdos de Paz reconocían la necesidad de que el Estado aumentara el gasto social hasta 50\% para el año 2000 con respecto al de 1995. Todo ello obligaba, si no se quería aumentar el déficit fiscal, a elevar la carga tributaria.

A mediados de los noventa nos encontramos con una situación complicada. A la tradicional cultura de evasión fiscal y la oposición firme de las élites guatemaltecas a cualquier aumento de la presión fiscal se le añaden las consecuencias de las propias políticas de ajuste. En efecto, los ingresos del fisco se van a ver afectados negativamente por medidas como la disminución de aranceles, resultado de la apertura externa, o la reducción de impuestos a las empresas para estimular la inversión. ${ }^{8}$ Las zonas francas son el ejemplo más evidente de ello. Precisamente los sectores de actividad más dinámicos quedan eximidos del pago de algunos impuestos, lo que merma la propia capacidad del crecimiento económico para elevar los ingresos fiscales.

8 Un análisis más detallado de estos efectos para el conjunto de la región centroamericana puede obtenerse en Fuentes (2006). Por citar un ejemplo, el autor estima que la reducción de la carga tributaria por la apertura externa se situaría en alrededor de 0.8 por ciento del PIB.

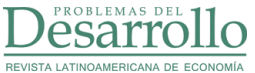


En este contexto, se plantea la necesidad de un "pacto fiscal" que siente las bases de la futura política fiscal, el cual se firma en mayo de 2000 con el pretendido consenso de entre quienes formaron parte del proceso, aunque se ha encontrado con importantes dificultades para su aplicación (PNUD, 2001:47-53). Los orígenes de este pacto se hallan en el incumplimiento de los compromisos asumidos en materia fiscal en los Acuerdos de Paz, además del convencimiento de que una reforma tributaria como la que se precisaba sólo se haría efectiva si era fruto de la concertación social (Fuentes y Cabrera, 2006). La oligarquía había vetado en cuatro ocasiones entre 1980 y 1999 (mediante presión política y recursos de inconstitucionalidad) reformas tributarias puestas en marcha por diferentes gobiernos, aunque hubieran sido aprobadas por el Parlamento.

En dicho documento nuevamente se recogen las necesidades de aumentar el gasto social, la inversión pública y la carga tributaria a la vez que se reitera el compromiso con el equilibrio presupuestario propio de las políticas de ajuste: el déficit fiscal no debe superar $1 \%$ del PIB.

A partir de ahí se logra elevar modestamente la carga tributaria aunque en 2005 todavía no se había conseguido alcanzar la meta propuesta de 12\% del PIB.

Pero lo más preocupante, desde el punto de vista redistributivo, es que este aumento va acompañado de una tendencia regresiva en la recaudación. En efecto, la elevación del Impuesto al Valor Agregado (IVA) (primero de 7 a 10\% en 1996 y tras la firma del Pacto Fiscal hasta 12\%) ha sido el principal instrumento utilizado. Y ello a pesar de que tanto en los Acuerdos de Paz como en el Pacto Fiscal se reconocía que las reformas debían aumentar el carácter progresivo del sistema tributario. El resultado está siendo precisamente el contrario. El IVA ha pasado de representar 36\% de la carga tributaria en el periodo 1990-1995 a $48 \%$ entre 1996 y 2002. Por el contrario el Impuesto sobre la Renta de las Personas Físicas (IRPF) ha disminuido su participación de $22 \%$ a $13 \% .^{9}$

Desde el punto de vista del gasto social, los logros son algo mayores aunque todavía modestos para la situación del país e incluso para los compromisos asumidos; además nos encontramos con importantes desigualdades entre unos sectores y otros. Como se aprecia en la gráfica 1, la participación del gasto social en el PIB se ha elevado de niveles inferiores a 4\% en 1990 a otros cercanos a 6\% en 2004. Por sectores, encontramos en un extremo la educación y el desarrollo urbano y rural como los que

9 Cálculos realizados con base en la información de Agosin, Barrex y Machado (2005:160). En el citado trabajo de Fuentes (2006) se puede encontrar un análisis similar para el conjunto de la región centroamericana.

Vol. 39, núm. 155, octubre-diciembre / 2008

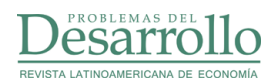


han experimentado un mayor crecimiento frente a la salud y asistencia social, cuya participación ha disminuido (PNUD, 2006: 342).

A pesar de estos aumentos el papel redistributivo sigue en cuestionamiento: según datos del Banco Mundial (BM) (2003:138), el quintil de ingresos más altos recibe casi $46 \%$ del gasto público en programas de protección social, mientras que el quintil más bajo recibe tan sólo $8 \% .^{10}$

En definitiva, para valorar con mayor precisión el posible alcance de estos cambios en la política fiscal no hay que olvidar tres aspectos: en primer lugar, el gasto público y el social siguen siendo bajos no sólo en relación con el promedio de la OCDE, sino también de América Latina; en segundo lugar, los logros alcanzados han sido en la mayoría de los casos inferiores a los compromisos asumidos en dichos Acuerdos de Paz; por último, no hay que olvidar que el aumento del gasto público ha sido posible sobre todo por el aumento de impuestos indirectos, lo que indicaría una tendencia regresiva de los ingresos tributarios. ${ }^{11}$

La política comercial como eje vertebrador del ajuste externo. En Guatemala el ajuste externo se presentó como un conjunto de medidas que se ponían en marcha con el objetivo de transformar la estructura productiva de un país para mejorar su inserción externa. El aumento de las exportaciones llevaría consigo una reducción del déficit comercial (origen del endeudamiento) y contribuirían al crecimiento económico. Por tanto, la existencia de este ajuste presupone que el problema se encuentra en la capacidad exportadora, en la competitividad de los países, supeditando otras medidas al intento de cumplimiento de ese objetivo.

Será en este ámbito donde más se aprecie el carácter subordinado que las reformas estructurales adoptan en economías como la guatemalteca. Supeditado a las necesidades e intereses del capital extranjero que actuará, eso sí, en connivencia con ese grupo de "empresarios modernizantes" citado más arriba. Esta situación se comprueba en dos políticas concretas relacionadas entre sí:

10 Mostramos estos datos no para dar la razón a quienes, apoyándose en ellos, justifican la necesidad de reducir el gasto público por su nula o negativa aportación redistributiva. Nuestro objetivo es distinto: incidir en la necesidad de reformar la estructura de esos gastos para que sí tengan un efecto redistributivo.

11 Algunos estudios centrados en la región latinoamericana señalan cómo en muchos países la distribución del ingreso tras los impuestos se vuelve más concentrada que antes de ellos. Los datos permiten comprobar esta situación en el caso de El Salvador, Honduras, Nicaragua y Panamá (y todo parece indicar que Guatemala seguiría una tendencia similar) (Fuentes, 2006:20 y Gómez Sabaini, 2005:54-56), así como en la mayoría de las naciones del Cono Sur (Gómez Sabaini, 2006:32).

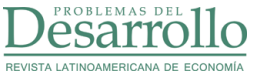


i) La apertura comercial y el fomento de nuevas exportaciones.

ii) El aumento de la participación de capital extranjero en los sectores estratégicos y más dinámicos de la economía que han experimentado de forma masiva procesos de privatización y eliminación de restricciones al capital extranjero. En la mayoría de los casos ha sido precisamente este capital extranjero el que ha liderado el avance de los productos no tradicionales.

Al tener en cuenta la trayectoria económica de Guatemala y su situación a principios de los noventa, resulta difícil creer que la apertura comercial indiscriminada - por muy acompañada del fomento a las exportaciones que estuviera - pudiera transformar la estructura productiva al reducir el déficit comercial. Lo que sí llevaba aparejada esa "transformación" de la estructura productiva era la insistencia en una competitividad basada en los bajos costos laborales. Sin duda, a priori, ello no parecía resultar muy positivo para la mejora de las condiciones laborales (tal vez sí para la creación de empleo), sobre todo en un contexto marcado por las crecientes exigencias de la "competitividad internacional".

Si nos centramos en los contenidos concretos de esa política comercial, podemos destacar dos ejes fundamentales:

i) La reducción de aranceles y la supresión paulatina de medidas no arancelarias. El nivel medio de protección arancelaria pasó de 30\% en 1980 a 10\% en 2000. Como resultado, las importaciones aumentaron rápidamente, pasando de representar $21.6 \%$ del PIB en 1990 a más de $28 \%$ en los últimos años (véase gráfica 2).

ii) El fomento de las exportaciones. A finales de los setenta y estimuladas por la Agencia Internacional de Desarrollo de Estados Unidos (EU) (Petersen, 1992: 3-4), en Guatemala se ponen en marcha diversas medidas encaminadas al fomento de las exportaciones, sobre todo de los denominados productos no tradicionales. Dentro de éstos destacan la agroexportación (vegetales, frutas, semillas y plantas ornamentales) y la maquila o "manufacturas para la exportación" (a las que recientemente se le están uniendo los "servicios para exportación", call centers). En gran parte ello responde a la pérdida de competitividad de productos estadounidenses que pretende ser recuperada con la deslocalización hacia países con costos laborales más bajos.

Entre las medidas adoptadas, las de mayor trascendencia fueron: i) la aprobación de un régimen fiscal especial que desde 1989 se extendió a todas las empresas expor-

Vol. 39, núm. 155, octubre-diciembre / 2008

Dessarrobllo 
tadoras de productos no tradicionales; este régimen fiscal se caracterizaba por la exoneración —en algunos casos temporal y en otros definitiva— de diversos impuestos como el de sociedades; ii) la creación de una gremial de exportadores de productos no tradicionales financiada en parte por la cooperación al desarrollo estadounidense que mantiene como objetivo el fomento de estas exportaciones; y iii) la firma de la Iniciativa de la Cuenca del Caribe (que ampliaba las preferencias de estos productos en su ingreso al mercado estadounidense) seguida por otros acuerdos comerciales entre los que destaca recientemente el Dominican Republic-Central America Free Trade Agreement, (DR-CAFTA, es decir el Tratado de Libre Comercio de EU, Centroamérica y República Dominicana) que entró en vigor en 2007.

Los resultados en cuanto al principal objetivo perseguido, el aumento de las exportaciones, han sido irregulares en el tiempo pero modestos en términos generales. La gráfica 2 habla por sí sola. Las exportaciones han pasado de 16\% del PIB en 1990 a 10.6 en 2004.

Gráfica 2

Evolución de la balanza comercial 1990-2006

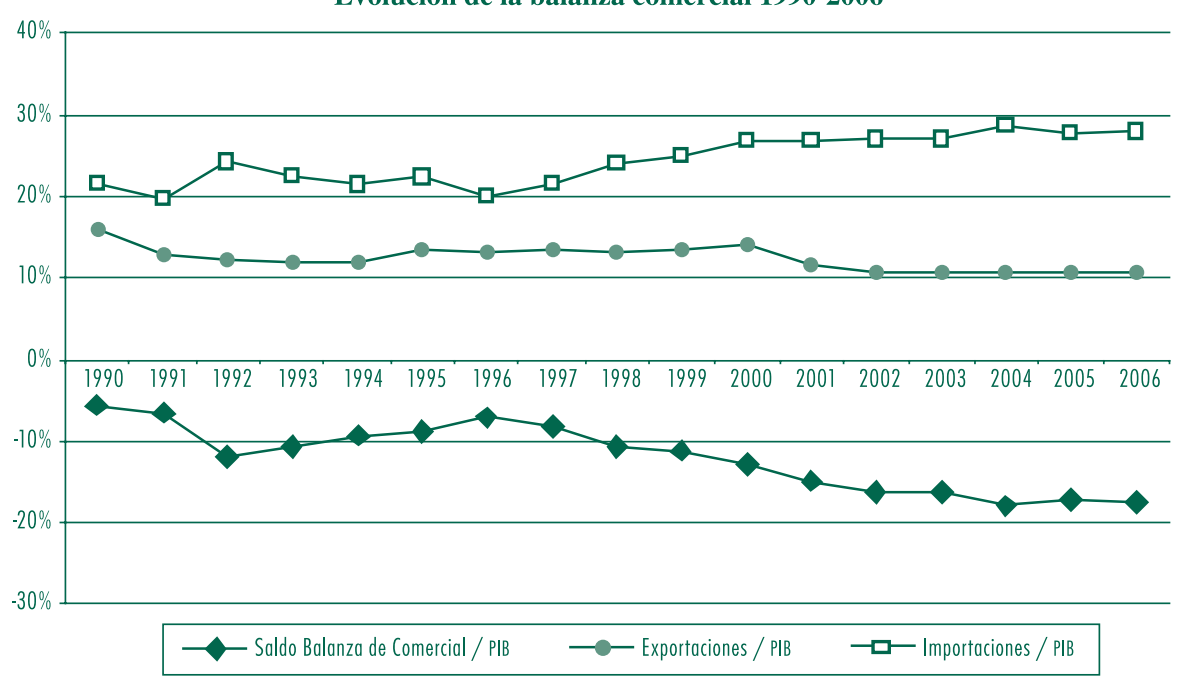

Fuente: Banco de Guatemala.

Desde la perspectiva de la diversificación del patrón exportador (objetivo perseguido también por estas medidas, dada la fuerte concentración del mismo), a primera vista los logros han sido mayores: las exportaciones tradicionales han cedido terreno 
a la participación de las no tradicionales, perdiendo peso así los productos primarios frente a los manufacturados..$^{12}$ Algunos de estos sectores han alcanzado una importancia significativa para la economía del país y no sólo en términos de exportaciones. Según la VESTEX, ${ }^{13}$ la industria de textil y confección representaba en 2007 alrededor de $8 \%$ del PIB y durante el periodo 1996-2007 había ocupado de media a un total de 85,000 trabajadores, lo cual supone $30 \%$ del empleo generado por la actividad exportadora de productos no tradicionales.

Gráfica 3

Guatemala: distribución de las exportaciones no tradicionales

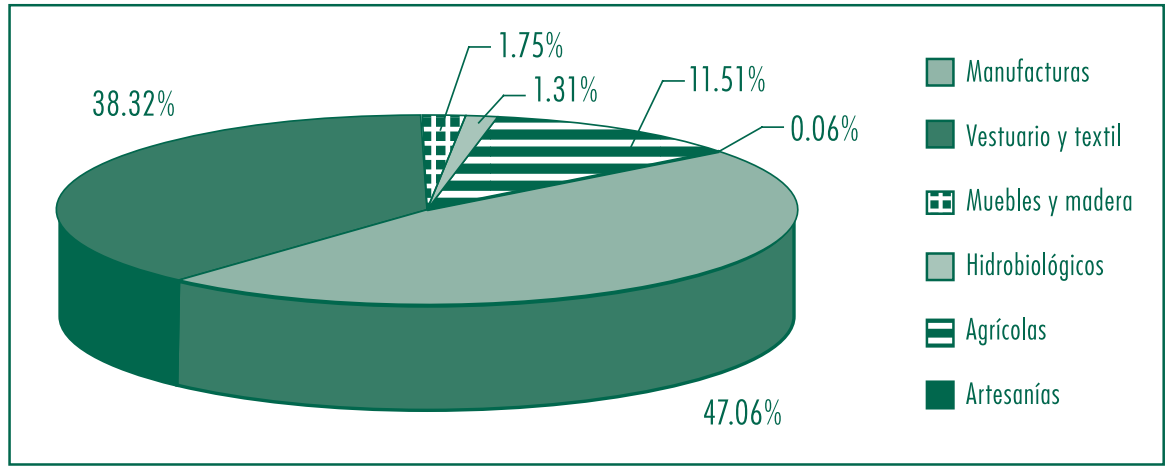

Fuente: Asociación Guatemalteca de Exportadores.

La firma de acuerdos de integración como el DR-CAFTA parece reforzar aún más esta dinámica en la medida en la que es el mercado estadounidense el principal destinatario de este tipo de productos. ${ }^{14}$

Sin embargo, se trata sobre todo de productos de baja y media tecnología, mientras que los de alta tecnología apenas han modificado su participación.

Ello significa que el potencial exportador se centra en productos intensivos en mano de obra o recursos naturales donde las condiciones laborales son precarias. No

12 Según las estadísticas del Banco de Guatemala, las exportaciones de productos tradicionales (café, algodón, azúcar, carne y cardamomo) han pasado de representar 56.1 por ciento en 1980 a 23.6 en 2006.

13 Comisión de Textiles y Vestuarios Textiles de la Gremial de Exportadores de Productos No Tradicionales.

14 Cerca de $40 \%$ de lo que se exporta a EU viene representado por el sector "vestuario y textiles" (Banco de Guatemala. Estadísticas sobre comercio exterior). 
Gráfica 4

Guatemala: contenido tecnológico de las exportaciones

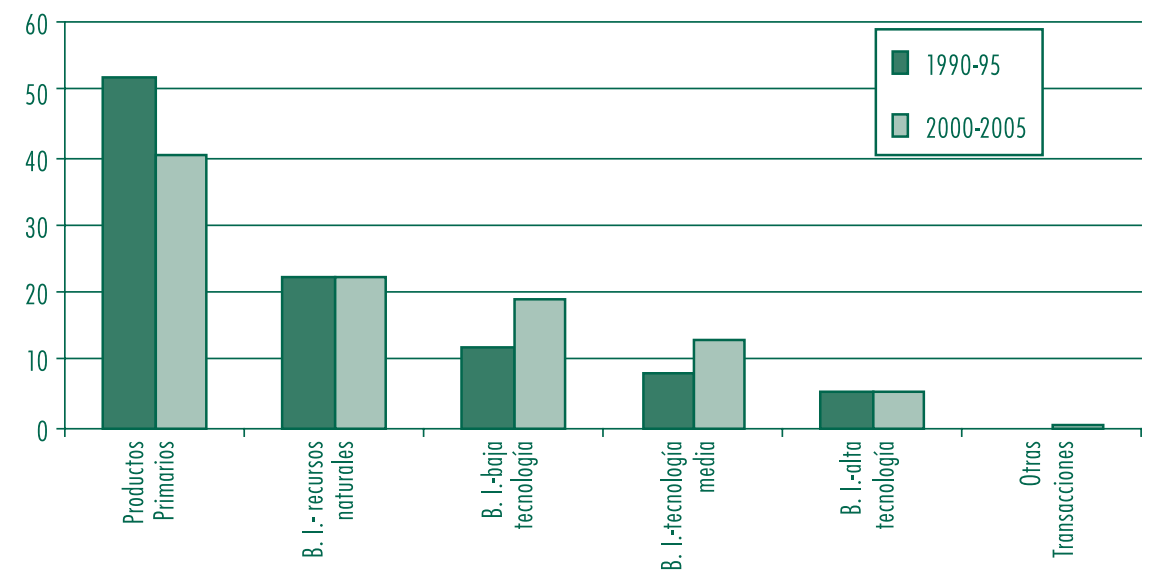

Fuente: CEPAL (2006): panorama de la inserción internacional de América Latina y El Caribe, Anexo estadístico.

en vano un reciente estudio refleja que es precisamente en las actividades agrícolas y en la industria manufacturera de exportación (la maquila) donde se concentra la mayoría del trabajo informal, sobre todo en el ámbito rural [Centro de Investigaciones Económicas Nacionales (CIEN), 2007:101]. Además la competencia feroz de los productos asiáticos o los vaivenes de la demanda estadounidense obligan a una constante contención de los costos laborales que en muchas ocasiones se traduce en un aumento de la informalidad. ${ }^{15}$

$\mathrm{Al}$ resumir todo lo dicho en este apartado, un análisis de las principales medidas que han conformado las políticas de ajuste en Guatemala nos permite identificar de manera clara los mecanismos con que se va a afectar negativamente a los trabajadores:

1) Las políticas monetaria y fiscal aplicadas han impedido un mayor crecimiento económico y han mermado las posibilidades del Estado de contribuir de forma más positiva al mismo. No olvidemos que estamos en un contexto de políticas fiscales regresivas por lo que las mejoras en los ingresos quedan prácticamente subordinadas a la recuperación del crecimiento económico y a la magnitud del mismo.

2) Una política comercial orientada a la transformación de la estructura productiva y exportadora que no resuelve el déficit comercial. Además, esa política comer-

15 Este hecho ha sido corroborado por empresarios y trabajadores del sector entrevistados. 
cial plantea una mejora de la competitividad internacional basada en actividades sometidas a un permanente ajuste de sus costos laborales, lo que tendrá sus implicaciones en términos de salarios y condiciones laborales.

Llegados a este punto es importante insistir en que dicha especialización no responde sólo a factores internos (como la propia abundancia de mano de obra o los costos laborales bajos) sino al carácter dependiente y subordinado de la inserción exterior. El capital extranjero, sobre todo estadounidense, no solamente es quien promueve el avance de esta industria en el país, sino quien además marca los límites de su propio desarrollo. En efecto, los distintos acuerdos comerciales firmados han conformado las líneas básicas de especialización del país. Ello ha sido posible con el establecimiento de unas normas de origen que entorpecen o facilitan a conveniencia el desarrollo de la cadena hilo-textil-confección [Comisión Económica para América Latina y el Caribe (CEPAL), 2008 y Paz, 2002].

\section{Evolución de las condiciones laborales y de vida de los trabajadores}

Hemos tratado de mostrar cómo las reformas se convierten en el elemento determinante del posterior reordenamiento, ante la crisis suscitada por el agotamiento del patrón de crecimiento. Tal y como hemos enunciado en las páginas anteriores estas transformaciones han tenido efectos para los ingresos y las condiciones laborales y de vida de los ciudadanos. El objetivo de este apartado es mostrar precisamente esas implicaciones y comprobar que en términos generales han implicado el mantenimiento o incluso el empeoramiento de una situación ya de por sí precaria. Mediante diversas fuentes se dejará constancia de la caída de los ingresos laborales y del deterioro de las condiciones de trabajo. Además se mostrará cómo lo novedoso, frente a otras épocas, es que este deterioro se ha hecho por medio de una creciente informalidad que está adquiriendo rasgos distintivos. La informalidad se va nutriendo de trabajadores "excluidos" del sector formal, en gran parte como resultado del proceso de ajuste y de la creciente competencia internacional.

\section{Ingresos y condiciones laborales}

En la gráfica 5 se muestra información sobre la evolución de los salarios reales promedio de los trabajadores cotizantes [afiliados al Instituto Guatemalteco de Seguridad Social (IGSS)], es decir, de los trabajadores del sector formal de la economía. Como 
se observa, tras la caída espectacular que experimentaron los salarios reales durante buena parte de la década de los ochenta, el inicio de los noventa marca un punto de inflexión coincidiendo con la transición democrática y una cierta recuperación de los niveles de crecimiento económico. Desde finales de los noventa en algunos sectores, de forma más generalizada desde el 2000, el salario real promedio está prácticamente estancado, declinando otra vez en los dos últimos años. A pesar de la tendencia alcista de buena parte de los noventa, en la actualidad el salario real en muchos sectores no ha recuperado los niveles anteriores al estallido de la crisis.

Gráfica 5

Evolución de los salarios reales

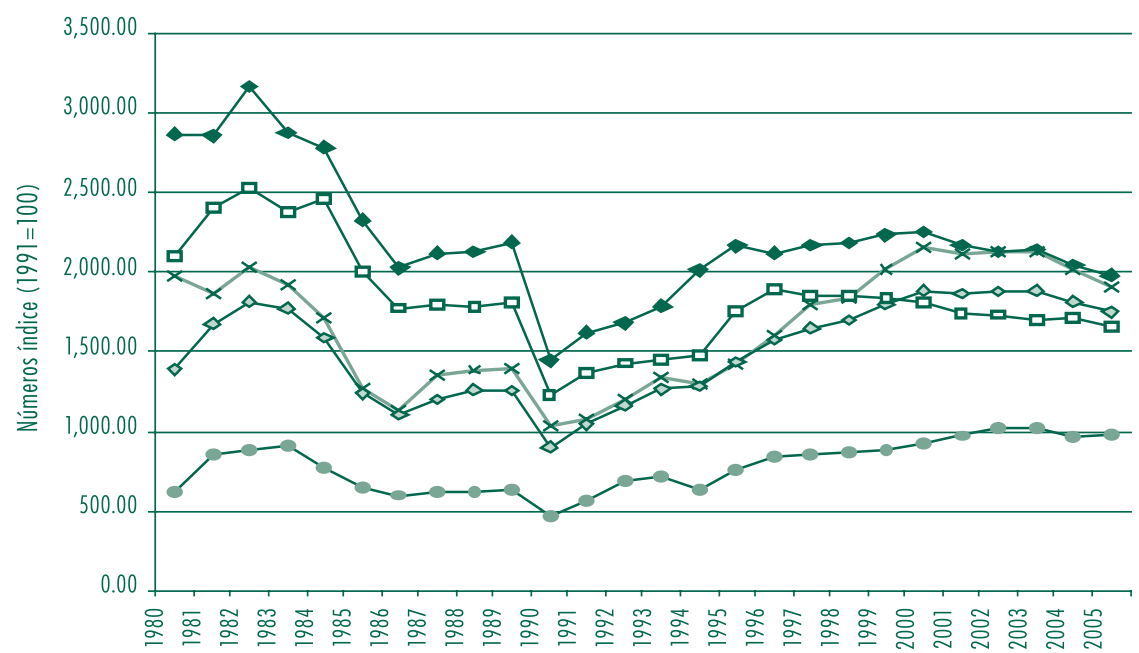

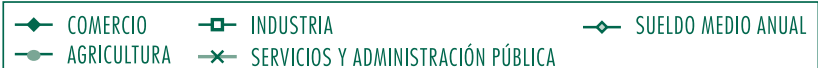

Fuente: Instituto Guatemalteco de Seguridad Social.

Por ello, en la actualidad el salario nominal promedio en el sector formal de la economía es insuficiente para cubrir el costo de la Canasta Básica Vital (CBV) y en algunos sectores como el de la agricultura tampoco el de la Canasta Básica de Alimentos (CBA). Además, durante buena parte de la década de los noventa el costo de ambas creció mucho más rápido que los salarios reales. Ello quiere decir que el aumento de los precios fue más acusado en los productos de primera necesidad que en otro tipo de artículos como resultado de la propia apertura comercial, entre otras razones. 
Otro indicador que nos muestra el deterioro de la capacidad adquisitiva de los trabajadores del sector formal es el que relaciona el ingreso medio de la población económicamente activa de un país y las respectivas líneas de pobreza. En Guatemala, dicho ingreso ha pasado de ser 3.5 veces el valor de la línea de pobreza en 1989 a tan sólo 2.9 (CEPAL, 2007: Anexo estadístico, cuadro 24).

Gráfica 6

Sueldos medios mensuales e ingresos laborales y su relación con la Canasta Básica de Alimentos y la Canasta Básica Vital
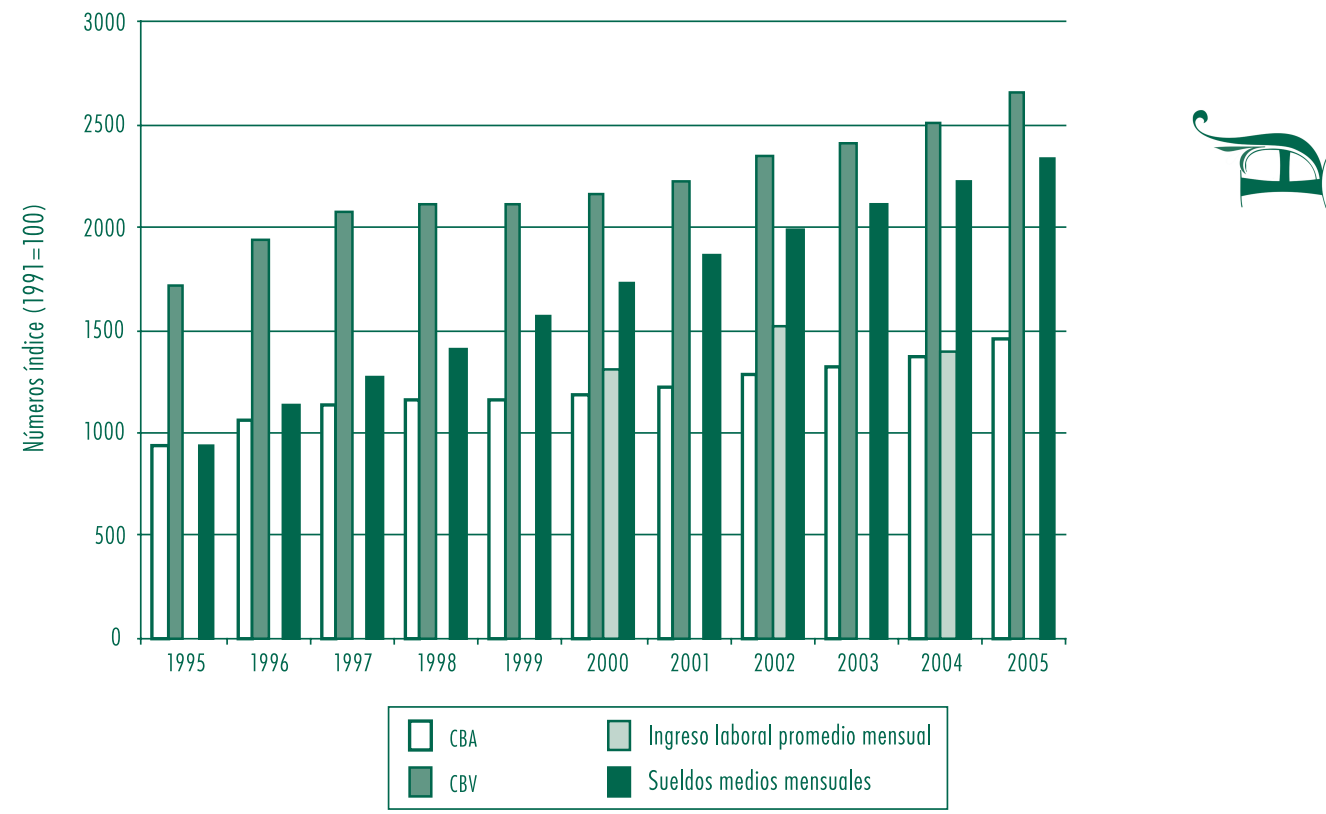

Fuente: Elaboración propia con base a datos del Instituto Nacional de Estadística y del Instituto Guatemalteco de Seguridad Social.

Pero el deterioro no se ha dado sólo en los ingresos, sino de forma más amplia en el conjunto de las condiciones laborales, ya de por sí bastante precarias. En muchos sectores son frecuentes las largas jornadas de trabajo, las pésimas condiciones de higiene y salubridad, la discriminación sexual, la violación de derechos laborales, etcétera. ${ }^{16}$

16 La falta de un registro sistemático impide dar información más detallada sobre estas cuestiones. Sin embargo, se pueden acudir a los numerosos estudios de caso que se han realizado sobre la situación en fábricas concretas. La suma de todos ellos nos permite concluir que estamos ante una situación bastante generalizada. Ejemplos de estos análisis los encontramos en Human Rights Watch 2002, CALDH-ASEPROLA 2004, para el caso de la maquila, y Schrage 2004 para el caso del café. 
Aunque las causas que hay detrás de este deterioro son prácticamente las mismas en todos los países, la reducción de los costos laborales y el mecanismo de aplicación difieren según los casos. En otros países el deterioro de las condiciones laborales ha sido fruto en gran parte del proceso de desregulación y flexibilización del mercado laboral. En apariencia este proceso no se ha dado en Guatemala. De hecho, la legislación laboral guatemalteca vigente antes de las reformas y el reiterado incumplimiento de algunos de los más mínimos derechos laborales motivaron la aprobación de leyes en favor de los trabajadores. Entre 1992 y 2001 se aprobaron cuatro reformas al Código de Trabajo. Las presiones internacionales, sobre todo las recomendaciones de la Organización Internacional del Trabajo (OIT), favorecieron también este proceso. Pero al margen de la aprobación de estas leyes, las deficiencias de la justicia y de la inspección de trabajo están permitiendo un aumento informal pero real de la flexibilidad del mercado de trabajo. ${ }^{17}$

No son necesarias leyes que eliminen la jornada laboral máxima obligatoria, que abaraten el despido o que reduzcan o supriman el salario mínimo para que las empresas adapten estos parámetros a la "evolución de la demanda". De hecho, una parte significativa de trabajadoras de la maquila, independientemente de si tienen contrato o no, no son indemnizadas por despido, o laboran más horas extras de las permitidas sin que se les remunere y su salario está por debajo del mínimo legal. ${ }^{18}$ En los llamados call center las condiciones no parecen ser mucho mejores: con salarios algo más altos, también son frecuentes la inestabilidad laboral, la obligatoriedad de realizar horas extras o firmar hojas de baja voluntaria sin fecha. ${ }^{19}$

Además, resulta preocupante que la respuesta a esa creciente violación de los derechos laborales sea la proliferación de códigos de conducta voluntarios y no reforzar la legislación laboral y las prácticas jurídicas al respecto.

17 Para ampliar esta información con datos más concretos pueden consultarse entre otros a Morales y Arrieta, 2003; Barán y Tzay, 2004; ASEPROLA y CALDH, 2004.

18 El salario mínimo en 2005, tanto para las actividades agrícolas como no agrícolas, era insuficiente para cubrir el costo de la CBA. Para el presidente de la comisión laboral del CACIF (Comité Coordinador de Asociaciones Agrícolas, Comerciales, Industriales y Financieras), el salario mínimo no necesariamente tiene que cubrir todos los productos de la canasta básica, de lo contrario se convierte en un salario máximo (declaraciones extraídas de la web del Ministerio de Trabajo y Previsión Social).

19 El desarrollo relativamente novedoso de este sector en Guatemala condiciona la ausencia de trabajos o registros sistemáticos que nos permitan dar una información más detallada sobre las condiciones laborales de esta actividad que todavía no representa un porcentaje significativo del empleo. A pesar de ello se pueden consultar los trabajos de Cuevas y Bolaños (2007), Reynolds (2008) y Thirión (2007). 


\section{La informalidad ${ }^{20}$}

Al margen de lo que ocurra en el sector formal, sin lugar a dudas el indicador que muestra más claramente ese deterioro de los ingresos y las condiciones laborales es el aumento de la informalidad.

\section{Concepto y tendencias actuales}

Desde hace ya muchas décadas la informalidad ha sido uno de los rasgos característicos de la economía guatemalteca y una de las expresiones más evidentes de las limitaciones de los distintos modelos de crecimiento para garantizar unas condiciones de trabajo dignas para la mayoría de la población. Sin embargo, la situación actual muestra rasgos propios que hacen especialmente preocupante la persistencia y agudización de este fenómeno. Veamos los más destacables para el caso guatemalteco:21

i) En primer lugar, la informalidad ha dejado de ser (si es que alguna vez lo fue de forma mayoritaria en los países en desarrollo) una especie de "estadio intermedio" entre el desempleo y la actividad formal. Es decir, no estamos hablando de trabajadores ni de actividades que tiendan, en el medio o largo plazo, a ser absorbidos por el sector formal. El rumbo seguido en las últimas décadas apunta más bien en el sentido contrario. Y ello se explica porque el impulso de determinadas actividades intensivas en mano de obra surge de la necesidad de abaratar costos laborales que se acabará manteniendo de forma indefinida en el tiempo por la creciente competencia internacional. También las propias características de la demanda presionan en este mismo sentido. Es una demanda fuertemente elástica por lo que modificaciones en el precio hacen variar mucho la demanda. Esto obliga a contener la subida de precios, presión que los comercializadores trasladan a los productores.

Se trata también de una demanda muy cambiante. Para mantener los ritmos de consumo se introducen cambios continuos de tendencias. Ello implica la necesidad de desarrollar un proceso productivo altamente flexible que condiciona la existencia de largas jornadas de trabajo para sacar adelante los pedidos y obliga a los empre-

20 De forma simplificada, entendemos por informalidad o sector informal a todas aquellas actividades económicas que contribuyen a la capacidad productiva de un país pero que no quedan registradas legalmente. Además de las evidentes consecuencias en términos de recaudación fiscal, para los trabajadores la principal consecuencia es que al no quedar registrados como tales pierden todos los derechos que en virtud de ello el Estado les reconoce. Para profundizar en el concepto y tendencias recientes de la informalidad desde distintas perspectivas pueden consultarse los trabajos de Benería (2004), Pérez Sáinz (2000), Perry et al. (2007).

21 En Benería (2004:71-75) se puede encontrar una exposición más amplia de los mismos. 
sarios a evitar a toda costa parar la producción, lo que podría significar el retraso de un pedido y la pérdida de un cliente.

En definitiva todo ello se traduce en una presión constante para abaratar costos laborales y lograr una máxima flexibilidad que en muchas ocasiones sólo es posible mediante relaciones laborales informales o cuasi informales. ${ }^{22}$

Con todos estos condicionantes entendemos por qué no se trata de un fenómeno coyuntural o pasajero sino que es fruto de los cambios en el modelo de crecimiento, sobre todo en la inserción externa. Verlo así nos permite entender el aumento de la informalidad no sólo como resultado de la dinámica económica interna, sino también de su relación con la dinámica económica mundial. Además muestra la complejidad y dificultad de las soluciones dado el escaso (pero no nulo) margen de maniobra de las políticas nacionales. Las grandes firmas, y en nuestro caso el capital transnacional, ocupan un lugar protagonista en el crecimiento de la informalidad por medio de fenómenos como la externalización y subcontratación.

En definitiva, lo que en los países desarrollados se ha traducido en un aumento de la precariedad o disminución de los estándares laborales, en los países en desarrollo ha dado lugar a un aumento de la informalidad pero el resultado es muy similar: un recorte de los costos laborales en aras de la recuperación de los beneficios y la mejora de la competitividad internacional.

ii) La expansión de la actividad informal va acompañada de un mayor reconocimiento de ciertos derechos políticos y sociales. Esto se hace visible en el caso guatemalteco por la finalización del conflicto armado con la firma de los Acuerdos de Paz y el proceso de transición democrática. Probablemente el ejemplo más claro de ello lo representen las mujeres que se han incorporado en las últimas décadas al trabajo asalariado en el sector de las manufacturas para la exportación.

Ello da lugar a diversas contradicciones. La primera, señalada por Benería (2004:73), quien sugiere que estas mujeres trabajadoras han fortalecido sus derechos individuales y han aumentado su autonomía al liberarse de ciertas formas de patriarcado a la vez que han pasado a ser sujetos de discriminación y explotación laboral.

Pero también se produce una situación caracterizada por el reconocimiento oficial de ciertos derechos individuales y colectivos a la par que aumentan las dificultades

22 Entendemos por cuasi informales aquellas relaciones laborales en las que aunque exista un contrato formal, las características del mismo o la actitud del empresario impiden de hecho que los trabajadores se puedan beneficiar de los derechos y beneficios que les aportaría una relación laboral formal. Ello resulta también muy frecuente en el caso de los call centers. 
para valerse de ellos. En un trabajo desarrollado en 2001 con trabajadoras guatemaltecas de este sector escuchábamos a las mujeres hablar de un cierto empoderamiento económico (por la obtención de un ingreso) pero limitado en lo social y político por las propias características de las relaciones y condiciones laborales que protagonizan. Es decir, en un contexto marcado por el fin de la represión —al menos la armada — y un mayor reconocimiento de derechos políticos y sociales, la incorporación de mujeres al trabajo asalariado apenas tiene efectos para ellas en cuanto al uso de estos derechos por carecer de un contrato formal. O lo que es más grave (y muy frecuente en el caso que nos ocupa) aunque haya un contrato formal, tampoco se les permite disponer de esos derechos: se les niegan los permisos para ir al médico pese a tener jornadas de 12 o más horas diarias, se despide a las mujeres que se afilian a un sindicato... (Paz Antolín y Pérez Orozco 2001:35-56). Es lo que antes denominamos relaciones laborales cuasi informales.

Valoración de la informalidad en Guatemala

La participación de los trabajadores afiliados al IGSS en el total de la PEA (población económicamente activa) ha disminuido de manera sistemática desde finales de los ochenta al pasar de $39.4 \%$ en 1980 a 19.8 en $2004 .{ }^{23}$ Según otras fuentes, el número de trabajadores en el sector formal e informal fue, en 1986, de 661,000 y 1,556,000 respectivamente. En 2003 los valores habían ascendido a 958,000 y 3,935,000 (Guerrero de Lizardi:2007:64). Ello significa que del total de trabajadores, los del sector informal pasaron de representar de 70\% a 80\%. Estimaciones del BM (2003:50) señalan que durante los noventa se perdió una media de 6,400 empleos del sector formal al año.

Existen importantes desigualdades entre departamentos y zonas urbanas y rurales: en el extremo con menor participación del trabajo informal (alrededor de 50\%) se encuentran algunas de las principales ciudades, como la propia capital; por el contrario, en algunas zonas rurales la informalidad abarca casi a 90\% de la población trabajadora. Estas desigualdades también se aprecian cuando hablamos de las diferencias étnicas: la informalidad afecta a $67 \%$ de trabajadores no indígenas frente a $89 \%$ de los que sí lo son (CIEN, 2007:63). Las diferencias entre hombres y mujeres trabajadoras también son marcadas: mientras que el crecimiento de la población masculina ocupada en el sector informal ha sido de $4.3 \%$ entre 1989 y 2002, el de la población

23 Información extraída de PNUD (2003:267 y 2006:348) con base en ENS 1989, ECONVI 2000, ENEI 2002 y 2004.

Vol. 39, núm. 155, octubre-diciembre / 2008

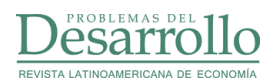


femenina ha sido de 7.4. Como consecuencia, los ingresos laborales promedio de las mujeres son significativamente inferiores a los de los hombres: en 2004 el ingreso laboral promedio de las mujeres era 519 quetzales inferior al de los hombres; entre 1989 y 2002 el diferencial entre el ingreso laboral promedio de los hombres y el de las mujeres aumentó en casi $60 \%$.

Los niños trabajadores constituyen junto con las mujeres el otro gran grupo que protagoniza el trabajo informal. Su número ha aumentado desde principios de los noventa tanto en términos absolutos como relativos, pasando de una tasa de participación en la PEA de $8.2 \%$ en 1994 a $20.1 \%$ en $2000 .{ }^{24}$ En 2000 casi un millón de niños entre 5 y 17 años trabajaba en Guatemala: 519,503 entre 5 y 14 años y 418,027 entre 15 y 17 años, lo que representa en cada caso más de $16 \%$ y $50 \%$ de la población infantil y adolescente del país. Casi 75 por ciento de los menores adolescentes que trabajan lo hace en el sector informal y es la pobreza la principal causa explicativa del trabajo infantil (OIT/IPEC/INE, 2003:30, 39 y 75). ${ }^{25}$

Todos estos datos corroboran la tesis con la que empezamos este apartado: la informalidad constituía ya un problema antes de las reformas pero éste no ha hecho sino aumentar tanto en términos absolutos como relativos. Además, es importante insistir en los nuevos rasgos que vienen caracterizándolo y que cuestionan una pronta y fácil solución del problema.

De hecho, el PNUD destaca en su informe de 2006 que entre 1989 y 2004 "los incrementos más sensibles en la proporción de personas que engrosaron la informalidad se observan entre quienes tienen educación secundaria (14 puntos porcentuales) y educación superior (11 puntos porcentuales). Ello sugiere que la educación por sí misma no es suficiente para asegurar que las personas tengan oportunidad de insertarse en la actividad económica formal" (PNUD, 2006:127). ${ }^{26}$

Por ramas de actividad, la agricultura y las manufacturas orientadas a la exportación son las que mayor porcentaje de trabajadores informales absorben: del total

24 El aumento del trabajo infantil es una problemática que excede la del propio aumento de la informalidad, con consecuencias más graves que las estrictamente relacionadas con este fenómeno. Para un análisis más amplio del problema se puede consultar OIT/IPEC/INE (2003).

25 El propio estudio de la OIT señala que existen ciertas diferencias metodológicas entre los censos de un año y otro que dificultan las comparaciones. A pesar de ello, concluye que no cabe la menor duda de que el trabajo infantil en Guatemala ha aumentado significativamente en los últimos 10-15 años.

26 No deja de resultar chocante que a pesar de estos datos las llamadas "reformas de segunda generación" insistan en que a las reformas estructurales tradicionales sólo les resta añadir más educación. 
de trabajadores informales encuestados por un reciente estudio del CIEN, 21 por ciento del total correspondía a cada uno de estos sectores. Ello parece confirmar la idea de que la estrategia exportadora adoptada en los últimos años se mantiene a costa de un crecimiento de la informalidad, de un empeoramiento de las condiciones laborales.

Desde el punto de vista de los ingresos, es preciso señalar que las propias características del trabajo informal impiden un registro sistemático de las condiciones salariales en las que éste se da. Sin embargo, las diferentes encuestas que sobre condiciones de vida o sobre empleo e ingresos se han realizado en los últimos años permiten obtener una aproximación a los mismos.

Según estas encuestas, el ingreso laboral promedio mensual en quetzales constantes ha caído durante el periodo $1989-2002$ en casi $14 \% .{ }^{27}$ Nos encontramos ante una tendencia claramente divergente: frente a la ligera recuperación de los salarios reales en el sector formal durante los noventa, al menos en algunas actividades, $e l$ ingreso real promedio, que incluiría los del sector formal y los del informal, ha caído estrepitosamente. La explicación obviamente está en la creciente informalidad y en el empeoramiento de sus ya de por sí bajos ingresos.

Según la última Encuesta Nacional de Empleos e Ingresos realizada por el Instituto Nacional de Estadística (2004), el salario promedio mensual en el sector informal era de tan sólo de 961 quetzales frente a los 2,495 del sector formal. Si tenemos en cuenta que en ese mismo año el costo de la CBA y la CBV eran respectivamente de 1,371.29 y 2,502.35 quetzales, queda claro que los ingresos obtenidos en el sector informal difícilmente llegan para cubrir las necesidades básicas, ni siquiera la de alimentación.

Sin duda, este deterioro de las condiciones laborales, materializado en un aumento significativo de la informalidad, ha tenido repercusiones para la calidad de vida de la población guatemalteca. Destacamos a continuación la evolución de tres indicado-

27 Si consideramos los datos de la última Encuesta sobre Empleos e Ingresos (ENEI 2004) la caída sería de $30 \%$. Esta última encuesta incorpora cambios metodológicos que permiten obtener información más precisa sobre el sector informal de la economía. Sin embargo, estos mismos cambios dificultan las comparaciones con encuestas anteriores. Dejando por ahora al margen las cifras absolutas, lo que parece evidente es que entre 2002 y 2004 la tendencia declinante de los ingresos laborales promedio se ha mantenido y, probablemente, se ha intensificado. Ello, además, sería coherente con la evolución de otros indicadores como el de los salarios reales del sector formal o el propio PIB, cuyos ritmos de crecimiento se han venido ralentizando en los últimos años.

Vol. 39, núm. 155, octubre-diciembre / 2008

Dessarrarollo 
res que, en nuestra opinión, reflejan muy claramente esta tendencia: magnitud de la pobreza, distribución del ingreso y condiciones alimenticias de la población. ${ }^{28}$

Si el salario es la principal fuente de ingresos para la mayoría de la población, la evolución del mismo habrá tenido un impacto significativo en la magnitud de la pobreza y en la distribución del ingreso.

Con respecto a lo primero, destacan dos tendencias paralelas: la reducción de la participación de la pobreza total medida en términos absolutos (que ha pasado de $62 \%$ en 1989 a 57\% en 2004) y el aumento de la pobreza extrema (también medida en términos absolutos) y de la profundidad de la pobreza ${ }^{29}$ (de $20 \%$ a $21.7 \%$ y de $8.9 \%$ a 12\% respectivamente) (PNUD, 2006:323).

Por otra parte, esa tendencia divergente entre los salarios del sector formal de la economía y los del sector informal no sólo ha aumentado la dispersión salarial, sino que ha contribuido a concentrar aún más la distribución del ingreso, cuestión que además se ha visto reforzada por la política fiscal. El coeficiente de Gini, principal indicador del grado de concentración de los ingresos, ha aumentado de 0.54 en 1989 a 0.57 en 2004. Este aumento en la concentración se ha debido a que la proporción del ingreso que corresponde a la quinta parte más pobre de la población se ha reducido de $3.1 \%$ en 1989 a 1.8 en 2004. A su vez, la participación del quintil más rico se ha elevado de 59\% a 60.2\% (PNUD, 2006:102).

Por último, es necesario analizar la evolución de la pobreza no sólo por los indicadores monetarios tradicionales (anteriormente expuestos), sino también por otros indicadores no monetarios. La evolución de alguno de ellos resulta sobre todo preocupante.

Éste es el caso de los indicadores relacionados con la situación alimenticia del país. El Banco Mundial reconocía en un informe publicado en 2003 que, desde el punto de vista de la malnutrición infantil, Guatemala se encuentra en la peor situación de toda América Latina y una de las peores de todo el mundo, sólo "superada" por

28 Hay muchos otros indicadores que tratan de valorar la evolución de las condiciones materiales de vida de la población que no aparecerán aquí reflejados. Algunos de ellos no han mejorado — sobre todo los de salud - y otros sí — particularmente los relativos a la educación y servicios básicos gracias al aumento del gasto social—. El objetivo de estos párrafos no es hacer una revisión exhaustiva de todos estos indicadores, para lo cual se recomienda consultar los distintos informes sobre Desarrollo Humano del PNUD. La idea es mostrar sólo los que están más directamente relacionados con la evolución de las condiciones laborales.

29 La profundidad de la pobreza mide la distancia promedio del ingreso o consumo de los pobres al valor de la línea de pobreza. 
Bangladesh y Yemen. Además, los indicadores muestran un empeoramiento en los últimos 10-15 años. En este periodo, según datos de CEPAL y la FAO (CEPAL, 2007:66), la proporción de personas subnutridas ha pasado de representar 16\% de la población (1990-1992) a 24\% (2000-2004).

El modelo agroexportador tradicional, que se ha visto reforzado con el fomento de los llamados productos no tradicionales, ha contribuido a ello. La superficie de cultivos destinados al consumo interno se ha reducido y la concentración de la tierra ha aumentado (Garoz, 2006 ${ }^{30}$ ). Si agregamos la crisis del café, un salario agrícola insuficiente y el encarecimiento de algunos productos básicos que ahora son importados, la combinación resulta explosiva para la seguridad alimentaria del país.

\section{Conclusiones}

Lo expuesto hasta ahora nos ha permitido profundizar tanto en las políticas de ajuste aplicadas en Guatemala como en las consecuencias que las mismas han tenido para los trabajadores, sobre todo los del sector informal.

Respecto a lo primero, la revisión nos ha permitido profundizar en las particularidades de las reformas aplicadas. Entre ellas destacan los esfuerzos en materia de presión fiscal y de gasto social. Precisamente ello es lo que ha permitido una mejora, aunque modesta, de indicadores relacionados con la educación o los servicios básicos.

Sin embargo, son muchas las evidencias que muestran el empeoramiento generalizado de las condiciones laborales, en particular de los salarios. A ello se le añade un aumento en la dispersión de los mismos por medio de la creciente informalidad. Si tenemos en cuanta también, aunque no ha sido objeto específico de nuestro estudio, la permanencia de los altos índices de concentración de la tierra, observamos cómo las reformas apenas han alterado los mecanismos redistributivos.

Desde una perspectiva laboral, la creciente informalidad ha sido el principal detonante de todo ello. Ésta es resultado de varios factores pero con este trabajo lo que hemos pretendido es mostrar cómo las reformas económicas aplicadas han insistido en un modelo de crecimiento que al menos hasta el momento ha favorecido claramente la expansión de la misma. Ello se ha debido a los bajos niveles de crecimiento

30 En este mismo documento el autor sostiene que en las reformas agrarias impulsada por el BM, la llamada "Reforma agraria asistida por el mercado", se ha dado prioridad a cuestiones como la liberalización del comercio agrícola, la integración de la agricultura en los tratados bilaterales y multilaterales, la biotecnología, la diversificación productiva, etcétera, dejando prácticamente de lado la cuestión del acceso a la tierra.

Vol. 39, núm. 155, octubre-diciembre / 2008

$\underset{\text { DeSarrollo }}{\text { PRR }}$ 
económico y, sobre todo, de inversión productiva que no han favorecido un aumento significativo del empleo. Además, las propuestas — tan protagonistas en las reformas- de mejorar la inserción exterior se han centrado en el desarrollo de sectores que no se caracterizan por las buenas condiciones laborales. El ámbito internacional marcado por la recesión estadounidense y la creciente competencia asiática no parecen, desde luego, favorecer un cambio de tendencia. Más aún si este deterioro de las condiciones laborales no se limita sólo al contexto guatemalteco sino que parece ser una tendencia global de los últimos 25 años.

\section{Bibliografía}

Agosin, Manuel, Alberto Barreix y Roberto Machado (ed.), Recaudar para crecer. Bases para la reforma tributaria en Centroamérica, Washington, DC, BID, 2005.

ASEPROLA-CALDH, Un vistazo por seis derechos laborales en Guatemala, Colección Antiflexibilidad, núm. 1, San José, ASEPROLA-CALDH, 2004.

AVANCSO, "La economía de Guatemala ante el ajuste estructural a comienzos de los noventa”, Textos para debate, núm. 13, Guatemala, AVANCSO, 1998.

Arrizabalo, Xabier (ed.), Crisis y ajuste en la economía mundial. Implicaciones y significado de las políticas del FMI y el BM, Madrid, Síntesis, 1997.

Baran Tzay, Pedro y Lidia Viviana Tzay Patal, Normativa laboral y obstáculos jurídicos, políticos, económicos y culturales en Guatemala, Guatemala, ASEPROLA-CALDH, 2004.

Benería, Lourdes, "Changing employment patterns and the informalization of jobs: General trends and gender dimensions", en Piras, Claudia (ed.), Women at work. Challenges for Latin America, Washington, DC, BID, 2004.

Banco Mundial, Poverty in Guatemala, Reporte núm. 24221, Washington, DC, BM, 2003.

CEPAL, Integración regional e integración con Estados Unidos. El rumbo de las exportaciones centroamericanas y de República Dominicana, México, CEPAL, 2008.

, Indicadores Sociales básicos de la subregión Norte de América Latina y El Caribe, México, CEPAL, 2007.
Crotty, James, Structural contradictions of the Global Neoliberal Regime, University of Massachussets Amherst, Political Economy Reseatch Institute (PERI), 2000.

Cuevas, Mario y Lisardo Bolaños, Oportunidades y riesgos en la liberalización del comercio de servicios: el caso de Guatemala, Guatemala, CIEN, 2007

Fuentes, Juan Alberto, "Retos de la política fiscal en Centroamérica", Serie Estudios y Perspectivas, núm. 64, México, CEPAL, 2006. y Maynor Cabrera, "Pacto Fiscal en Guatemala. Lecciones de una negociación" en Revista de la CEPAL, núm. 88, Santiago de Chile, 2006, pp. 153-165.

Ffrench-Davis, Ricardo, Reformas Para América Latina. Después del fundamentalismo neoliberal, Buenos Aires, Siglo XXI, 2005.

Garoz, Byron, Aplicación de las políticas agrarias del Banco Mundial en Guatemala: 1996-2005, Guatemala, Instituto de Estudios Agrarios y Rurales-IDEAR, 2006.

Gómez-Sabaini, Juan Carlos, "La tributación a la renta en el Istmo Centroamericano: análisis comparativo y agenda de reformas", Serie Macroeconomía del Desarrollo, núm. 37, Santiago de Chile, CEPAL, 2005.

, "Cohesión social, equidad y tributación. Análisis y perspectivas para América Latina", Serie Políticas Sociales, núm. 27, Santiago de Chile, CEPAL, 2006.

Guerrero de Lizardi, Carlos, "Evolución reciente y perspectivas de empleo en el Istmo Centroamericano", Serie Estudios y Perspectivas, núm. 78, México, CEPAL, 2007. 
Hammill, Matthew, "Growth, poverty and inequality in Central America", Serie Estudios y Perspectivas, núm. 88, México, CEPAL, 2007.

Martínez, José Florentino, "La informalidad en Guatemala: entre la acumulación y la sobrevivencia”, Documento de Trabajo del Centro de Estudios Urbanos y Regionales, Universidad San Carlos de Guatemala, 2008.

Maul, Hugo, Lisardo Bolaños, Jaime Díaz y Javier Calderón, Economía informal: superando las barreras de un Estado excluyente, Guatemala, CIEN, 2006.

Micheli Thirión, Jordi, "Los call centers y los nuevos trabajos del siglo XXI", en Confines 3/5, Monterrey, Instituto Tecnológico, enero-mayo 2007, pp. 49-58.

Morales, Luisa Eugenia y Leda Abadallah Arrieta, Flexibilidad laboral en las empresas maquildoras en Guatemala, Guatemala, ASEPROLA-AMES-INIAP, 2003.

OIT/IPEC/INE, Estudio cualitativo sobre el trabajo infantil en Guatemala. Informe Final, Guatemala, Serviprensa, 2003.

Paz, María José, "Maquila y paquete completo en Guatemala: desafíos e interrogantes ante la ampliación de la iniciativa de la cuenca del Caribe", en Revista Integración y Comercio, núm. 16, año 6, Buenos Aires, BIDINTAL, enero-junio 2002, pp. 191-211.

y Amaia Pérez, "El empleo en la maquiladora textil en Guatemala y las trans- formaciones en las relaciones de género", Anuario de Estudios Centroamericanos, volumen 27 (2), San José, pp. 35-55, 2001.

Pérez Sáinz, Juan Pablo, "Las cuentas pendientes de la modernización: tendencias laborales y sus efectos sobre la integración social en el Istmo Centroamericano", CA 2020, Documento de Trabajo núm. 5, mimeo, 2000.

Perry, Guillermo E. et al., Informality: exit and exclusion, Washington, DC, Banco Mundial, 2007.

Petersen, Kurt, "The maquiladora revolution in Guatemala", Occasional Paper Series 2, Orivelle H. Schell, Jr. Center for International Human Rights, Yale Law School, Connecticut, 1992.

Programa de Naciones Unidas para el Desarrollo, Informe Nacional de Desarrollo Huma$n o$, NNUU, Guatemala, varios años.

Schrage, Elliot, Promoting Internacional Workers Rights Trough Private Voluntary Initiatives: Public Relations or Public Policy?, US Department/The University of IOWA Center for Human Rights, mimeo, 2004.

Williamson, John, "What Washington means by policy reform?" en Williamson, John (dir.) Latin American Adjustment: How Much Happened?, Washington, DC, Institute for International Economics, 1990. 